\title{
Assessment of RC Frames for SD Limit State Using Nonlinear Methods of Analysis According to EN 1998-3
}

\author{
Aleksandra RADUJKOVIĆ, Đorđe LAĐINOVIĆ , Andrija RAŠETA
}

\begin{abstract}
Design of structures in seismically active areas according to EN 1998-1 includes a choice between two ductility classes, medium or high, without conditioning by other parameters or favouring any of them. The behaviour factor $q$ is applied as a global reduction factor of internal forces that would develop in the structure in the event of elastic response. According to EN 1998-3 a seismic assessment is determined by comparing the demands with the corresponding capacities. For ductile element, seismic demand and capacity are expressed in terms of chord rotation. The research in this paper was focused on the study of influence of the design ductility classes, as well as of the design seismic actions and the number of frames storeys, on seismic response of reinforced concrete frames designed according to European codes. Seismic performance evaluation of newly designed code-conforming structures is of interest, in order to identify any potential weaknesses and deficiencies in new structures that are designed with appropriate acceptable level of structural damage in the event of a design earthquake. The considered frames were evaluated for the significant damage limit state, for which the return period corresponds to the designed seismic actions. Nonlinear methods of analysis were used, which are the reference methods for assessing seismic performance. The frames designed for high class ductility manifested more favourable seismic performance and the frames designed for lower seismic action had lower values of demand/capacity ratio.
\end{abstract}

Keywords: chord rotation; nonlinear analysis method; RC frame; SD limit state

\section{INTRODUCTION}

Over the past few years performance-based design (PBD) approach is used in the seismic design and assessment of structures. This approach enables engineers to design structures with predictable seismic performance. Three main steps of PBD are: performance goals, seismic demands and seismic performance assessments [1]. Performance goals are based on defining the performance level, which determines the acceptable level of damage and the level of hazard that describes the expected seismic action at the site. The next step is estimation of seismic demands in primary and secondary seismic elements of a structure due to earthquake actions. The calculated seismic demands are compared with the corresponding capacities for different performance states. The performance criterion in the form of deformation measure is usually determined on the basis of experimental analyses to quantify the states of damage.

Performance levels, according to European code, are identified as limit states, and are linked with hazard levels. Seismic hazard describes earthquakes or earthquake effects and their frequency of occurrence [2]. In the current version of EN 1998-1 [2] there are two performance requirements (two performance levels): no collapse requirement, for design seismic action with a return period of 475 years; and damage limitation requirement, for seismic action with a return period of 95 years. Values of return periods for the seismic actions are not prescribed in EN 1998-1, they are only recommended, and they may be defined in the National Annexes. Estimated seismic demands are usually expressed in terms of force, for no collapse requirement, and in terms of deformation, for damage limitation requirement.

In recent years, society has begun to think more rationally about the dangers associated with earthquakes and wants to know about the performance of structures in relation to a possible earthquake [4]. EN 1998-3 [5] is the first European standard on seismic assessment and retrofitting of buildings. Among other things, the provisions of EN 1998-3 relate to providing the criteria for evaluation of the seismic performance of existing building structures. Besides the existing structures, evaluation of the seismic performance is also necessary for newly designed structures, in order to identify any potential weaknesses and deficiencies in new structures that are designed with appropriate acceptable level of structural damage in the event of a design earthquake. Unlike the design, structure assessment according to EN 1998-3 is carried out for three levels of performance. Performance levels refer to the degree of structure damage and are formulated in terms of the three limit states: near collapse (NC), significant damage (SD) and damage limitation (DL). Each limit state corresponds to different seismic hazard level. Return periods for the seismic action may be defined in National Annexes. Recommended values, for basic protection goals for ordinary new buildings, given in EN 1998-3, are: for NC limit state - 2475 years; for SD limit state - 475 years; and for DL limit state - 225 years. It should be noted that return period for SD limit state, for structure assessment, is equal to the one for no-collapse requirement, in seismic design of structures. Comparison of estimated demand and capacity depends on the type of structural element. For ductile element, seismic demand and capacity are expressed as deformation, whereas for brittle element as force.

Estimation of seismic demands is an important step and requires accurate modelling and analysis, but also the development of a structural model of reasonable complexity. EN 1998-3 provisions allow the use of four analysis methods for estimation deformation demands, two linear (equivalent lateral forces- linear static and modal response spectrum - linear dynamic) and two nonlinear (pushover-nonlinear static and time history - nonlinear dynamic) methods. In [6] the linear dynamics method of analysis and pushover method were compared in order to investigate the difference in terms of results and applicability in estimating the reinforced concrete (RC) frames designed to gravity loads. A general conclusion is that the estimated deformation values are more 
conservative when using linear analysis methods in comparison with the results of nonlinear method. Based on the application of the procedures given in EN 1998-3 in [7], it is assessed whether linear and nonlinear analysis methods lead to similar results of seismic safety through the relation of demand and capacity. The results showed that linear analysis methods, in case of considered frames, are not applicable for seismic assessment, while a comparative assessment between pushover and nonlinear time-history analysis leads to the conclusion that pushover results can generally be considered safe side compared to the results of nonlinear dynamic analysis. Multi-storey RC frame structure, designed according to the provisions of EN 1992-1 and EN 1998-1, was analysed in order to determine the displacement and chord rotation of element, by linear, nonlinear static and nonlinear dynamic analysis methods [8] and the results showed that the safety levels were linked to the accuracy of applied analysis methods. Calculation using elastic analysis (the simplest one) is more conservative with respect to safety verification compared to the one made by pushover analysis, which is more conservative than the most complicated nonlinear dynamic analysis.

In many cases nonlinear static analysis will provide more relevant information than elastic static or dynamic analysis. It will also indicate the weaknesses of a design, including story mechanisms or excessive deformation demands. This method enables monitoring development of yielding in structural elements as well as the progress of the overall capacity curve of the structure [9]. However, the pushover analysis cannot present dynamic phenomena with a large degree of accuracy. Nonlinear dynamic response may differ significantly, particularly in case of important higher mode effects. For regular low-rise structures in which higher mode effects are not very important and inelasticity is distributed rather uniformly over the height, the pushover analysis provides very good predictions of seismic demands[10]. Given the complexity of non-linear dynamic analysis in relation to the static one, this confirms the use of pushover analysis as relevant for seismic evaluation. Although the nonlinear time-history analysis is the most accurate seismic demand estimation procedure, the use of nonlinear static analysis is generally considered more appropriate in engineering practice. Furthermore, the pushover analysis should be used as a precursor to nonlinear response history analysis, to determine if the response history analysis is producing reasonable results[11]. The basic assumption used in pushover methods is that the response is controlled by the fundamental mode (structure vibrates predominantly in a single mode). This assumption is not always fulfilled, especially in case of tall or asymmetric buildings. In recent years, considerable research has been made to improve the traditional pushover analysis when higher mode effects are significant[12]. Nonlinear analysis methods require a suitable structure model, which includes post-elastic behaviour.

The assessment of structures may be determined for more performance levels, i.e. limit states, and the seismic demand must be estimated for appropriate seismic action. How many and what limit state should be checked according to EN 1998-3 is defined in National Annexes.
This paper presents the assessment of newly designed $\mathrm{RC}$ frames in accordance with European standards by using nonlinear analysis methods. The assessment refers to the deformation measure which is, according to EN 1998-3, expressed by chord rotation, and frames are assessed for SD limit state. Analysed RC frames are designed with different number of storeys, for two ductility classes, and two intensity values of seismic actions. The geometry of these frames is assumed using the principles of structural system simplicity, regularity in the plane and by elevation, in order to fulfil the conditions for designing structures desirable in seismically active areas. The purpose of this paper is to assess seismic response of newly designed structures and to determined possible influence of varied parameters, number of storeys, ductility classes and seismic intensity on seismic response.

In order to obtain better information about seismic response, besides verification of deformation measure which presents seismic demand on member level, seismic response at global level was estimated, too. Contemporary seismic codes permit a reduction in design seismic action, since the structure possesses significant overstrength and capacity to dissipate energy. Structural overstrength is generally expressed by overstrength factor which is defined as the ratio between actual and design lateral system strength [15]. When the actual strength is greater than the design seismic force, the structure is able, in the event of an earthquake stronger than the design one, to suffer relatively minor damage.

Nonlinear methods of analysis, both static and dynamic, were applied within the scope of this study. The chord rotation demands of all elements of the considered frames were evaluated and compared with corresponding he capacities for the SD limit state.

\section{SEISMIC RESPONSE ASSESSMENT ACCORDING TO EN 1998-3}

According to EN 1998-3 seismic assessment is determined by comparing the demands with the corresponding capacities. This checking is in terms of chord rotation for ductile elements, beams, columns and walls. In ordinary regular frame structures, the structural elements, beams and columns are generally slender elements with dominant flexure effects. In such elements, the ratio of the shear span to the depth of cross section is of greater value. The usual values are greater than 2,5 for columns and 3 for beams and their inelastic behaviour is inherently ductile [16]. Chord rotation involves the behaviour of the elements as a whole, easily relates to global measure of seismic response, such as interstorey drift, while at the same time it can point to failure at the local level [17]. Chord rotation is the angle between the tangent to the axis at the yielding end and the chord connecting that end with the end of the shear span. It is determined at the end of each element.

The expression for determining the values of element chord rotation capacity can be obtained from theoretical assumptions or based on experimental results. The expression obtained on the basis of theoretical (mechanical) approach is based on the plastic hinge length. The empirical expression, based on experimental data, was developed by Panagiotakos and Fardis [17], and almost 
equivalent expression was obtained on the basis of a large database of test results, by Biskins and Biskins and Fardis [16]. This expression refers to chord rotation of elements with rectangular compression zone and detailing for earthquake resistance, in case of flexure controlled failure. Depending on steel class, type of load, slipping of longitudinal bars, this expression was adopted in EN 19983 to determine total ultimate chord rotation capacity (for near collapse limit state) of concrete elements under cyclic load, and it may be calculated from the expressions:

$$
\begin{aligned}
& \theta_{N C}=\frac{1}{\gamma_{e l}} 0,016 \cdot 0,3^{v} \cdot\left[\frac{\max \left(0,01 ; \omega^{\prime}\right)}{\max (0,01 ; \omega)} \cdot f_{c}\right]^{0,225} \cdot\left(\frac{L_{v}}{h}\right)^{0,35} \cdot \\
& .25^{\left(\alpha \cdot \rho_{s x} \cdot \frac{f_{y w}}{f_{c}}\right)} \cdot 1,25^{100 \cdot \rho_{d}}
\end{aligned}
$$

where $\gamma_{e l}$ is 1,5 for primary seismic members and 1,0 for secondary ones; $v$ is the normalized axial force; $\omega, \omega^{\prime}$ are the mechanical reinforced ratio of the tension and compression, respectively, longitudinal reinforcement, $f_{c}$ is concrete compressive strength $(\mathrm{MPa}) ; L_{v}$ is shear span; $h$ is the depth of cross section; $\alpha$ is the confinement effectiveness factor; $\rho_{s x}$ is ratio of transverse steel parallel to loading $\mathrm{x}$ direction; $f_{y w}$ is the stirrup yield strength $(\mathrm{MPa})$ and $\rho_{d}$ is the steel ratio of diagonal reinforcement in each diagonal direction. Total chord rotation capacity for significant damage limit state is taken as $3 / 4$ of the total ultimate chord rotation capacity.

The element chord rotation capacity depends on geometrical and mechanical characteristics of the element and cross section, but it also depends on seismic input, and therefore it cannot be unambiguously determined, no matter that elements were previously designed with details for earthquake resistance. Axial force and shear span are values that depend on the seismic input. Normalized axial force and shear span to depth ratio (shear span index) represent, with confinement and concrete compressive strength, the parameters that significantly influence the value of ultimate capacity. With the increase in the normalized axial force, the ultimate value of chord rotation decreases, while with the increase of shear span index (to a certain value) the ultimate chord rotation capacity increases too [17]. In nonlinear analysis, verification at each point during the response is preferred, using the current value of axial force [16]. Shear span, based on the definition, can be determined as the ratio of bending moment and shear force at the end section.

When applying nonlinear static analysis, the determination of normal force and shear span would not be complex, which cannot be said for the application of nonlinear dynamic analysis. In order to simplify the verification, the ultimate chord rotation capacity can be determined considering axial force due to the seismic load combination, and value of the shear span can easily be assumed to be half of element length [20]. In this case, the element chord rotation capacity would be independent of the seismic input and would represent an internal element information. The chord rotation is, as is also defined in EN 1998-3, "equal to the element drift ratio, i.e. the deflection at the end of shear span with respect to the tangent to axis at the yielding end, divided by the shear span". In [16], the chord rotation is defined as the angle between the normal to section at a member end and the chord that connects two member ends.

In estimating the demand, the value of chord rotation can be obtained as a sum of two angles: nodal rotation (the rotation at the member end) and drift at the end of shear span (the rotation of the shear span) [20]. For columns, when the building due to seismic action is pushed laterally, the drift at the end of shear span is much larger than the nodal rotation. In this case, the chord rotation can be determined as a lateral drift at shear span end. The determination of chord rotation demand at beams is complex due to gravity load. It can be considered that the node rotation due to seismic action is greater than drift at the end of shear span due to gravity load, and for obtaining the chord rotation, the drift at the end of shear span is neglected.

\section{NUMERICAL EXAMPLES 3.1 Descriptions of Analysed Frames}

In this paper $16 \mathrm{RC}$ frame structures having different number of storeys (4, 6, 8 and 10), designed for two ductility classes (DCM and DCH) and two cases of seismic action $\left(a_{g}=0,2 g\right.$ and $\left.a_{g}=0,3 g\right)$ were analysed. RC frame structures are symmetrical in both directions, with 3 bays of $5 \mathrm{~m}$. The first storey is $3,5 \mathrm{~m}$, and the others are $3,0 \mathrm{~m}$ high (Fig. 1).
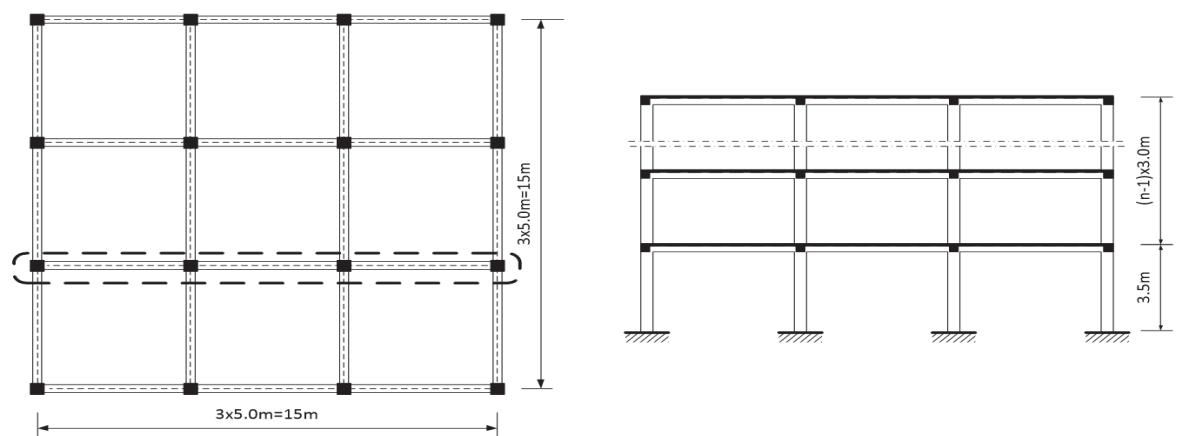

Figure 1 Floor plan and cross-section of considered inner frames

The beams of all RC frames have the same section, 30 $\times 45 \mathrm{~cm}$, and a slab thickness is $15 \mathrm{~cm}$. For columns, cross section dimensions depend on storeys and are equal to 45 $\times 45 \mathrm{~cm}, 50 \times 50 \mathrm{~cm}, 55 \times 55 \mathrm{~cm}$ and $60 \times 60 \mathrm{~cm}$ for 4,6 , 8 and 10 storeys frames, respectively (Fig. 2). RC frames structures meet the criteria of regularity in plane and can 
be analysed as $2 \mathrm{D}$ structures. Numerical analyses of the planar model of the inner frame with a $\mathrm{T}$-shaped section of beams of effective flange width $170 \mathrm{~cm}$ were conducted. C30/37 concrete class and S500 steel class C were used in the design of frames. Seismic action was represented by the horizontal elastic response spectrum of type 1 and soil category $\mathrm{C}$ with a ground acceleration $a_{g}=0,2 \mathrm{~g}$ and $a_{g}=$ $0,3 \mathrm{~g}$. Elastic analyses were carried out for two ductility classes, DCM and DCH, with the behaviour factors $q=3,9$ and $q=5,85$, respectively. The behaviour factors were determined by basic value of the behaviour factors for systems regular in elevation and with an adopted multiplication factor of 1,3 , corresponding to multistorey, multibay frames. The vertical actions, permanent and imposed loads, were also considered. Frame structures were designed according to EN 1992-1-1 and EN 1998-1. Adopted reinforcements, the longitudinal and especially transverse ones depend on fulfilment of special provisions conditional on the ductility. The same columns reinforcement of frame with a certain number of storeys, ductility class and seismic action was adopted. The reinforcement adopted for beams is not constant along the element but is different for sections at the ends and in the middle. For all medium ductility class frames and for 6 storeys high ductility class frames, adopted reinforcement is the same for all. In other frames, in order to meet the condition of the diameter limitation of longitudinal bars which pass through a beam - column joint to prevent the bond failure, the adopted reinforcement is different by storeys. The reinforcement for beam ends and columns for all analysed frames are shown (Tab. 1 - Tab. 4) where $m$ marked a number of leg stirrups. In these tables the frames are named depending on ductility class and intensity of design seismic action for which they were designed.
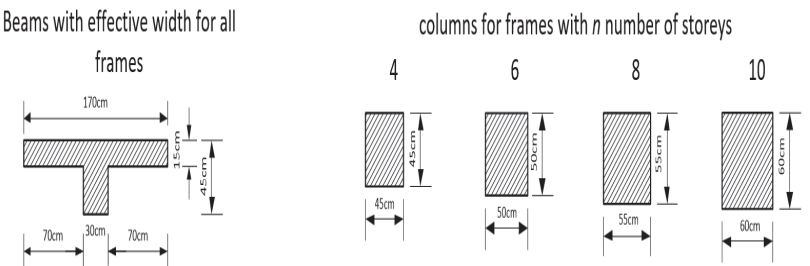

Figure 2 Cross sections of beams and columns in planar frames

Table 1 Reinforcement for beams ends and columns for 4-storey frames

\begin{tabular}{|c|c|c|c|c|c|c|}
\hline \multirow{3}{*}{\multicolumn{2}{|c|}{ 4-storey frames }} & \multicolumn{3}{|c|}{ BEAMS } & \multicolumn{2}{|c|}{ COLUMNS $45 \times 45 \mathrm{~cm}$} \\
\hline & & \multicolumn{2}{|c|}{ Longitudinal reinf. } & \multirow[t]{2}{*}{ Stirrup } & \multirow[t]{2}{*}{ Longitudinal reinf. } & \multirow[t]{2}{*}{ Stirrup } \\
\hline & & Top & Bottom & & & \\
\hline \multicolumn{2}{|c|}{ DCM $-0.2 g$} & $6 ø 14+6 ø 8$ & $4 ø 14$ & $ø 8 / 10 m=2$ & $12 ø 16$ & $ø 8 / 10 m=4$ \\
\hline \multirow{2}{*}{$\mathrm{DCH}-0.2 \mathrm{~g}$} & 1. -2 . & $5 ø 14+6 ø 8$ & $5 ø 14$ & $ø 8 / 8 m=2$ & \multirow{2}{*}{$12 ø 16$} & \multirow{2}{*}{$ø 8 / 7.5 m=4$} \\
\hline & 3. -4 . & $3 ø 14+6 ø 8$ & $3 ø 14$ & $ø 8 / 8 m=2$ & & \\
\hline \multicolumn{2}{|c|}{ DCM - $0.3 g$} & $6 ø 16+6 ø 8$ & $5 \varnothing 16$ & $ø 8 / 10 m=2$ & $12 ø 16$ & $ø 8 / 10 m=4$ \\
\hline \multirow{3}{*}{ DCH $-0.3 g$} & 1. & $6 ø 14+6 ø 8$ & $6 ø 14$ & $ø 8 / 8 m=2$ & \multirow{3}{*}{$12 ø 16$} & \multirow{3}{*}{$ø 8 / 7.5 m=4$} \\
\hline & 2. & $5 ø 14+6 ø 8$ & $5 ø 14$ & $ø 8 / 8 m=2$ & & \\
\hline & 3. -4 & $4 ø 14+6 ø 8$ & $4 ø 14$ & $ø 8 / 8 m=2$ & & \\
\hline
\end{tabular}

Table 2 Reinforcement for beams ends and columns for 6 - storey frames

\begin{tabular}{|c|c|c|c|c|c|}
\hline \multirow{3}{*}{6 - storey frames } & \multicolumn{3}{|c|}{ BEAMS } & \multicolumn{2}{|c|}{ COLUMNS $50 \times 50 \mathrm{~cm}$} \\
\hline & \multicolumn{2}{|c|}{ Longitudinal reinf. } & \multirow{2}{*}{ Stirrup } & \multirow{2}{*}{ Longitudinal reinf. } & \multirow{2}{*}{ Stirrup } \\
\hline & Top & Bottom & & & \\
\hline DCM - $0.2 g$ & $5 ø 16+6 ø 8$ & $4 ø 16$ & $ø 8 / 10 m=2$ & $12 ø 18$ & $ø 10 / 10 m=4$ \\
\hline $\mathrm{DCH}-0.2 \mathrm{~g}$ & $5 ø 14+6 ø 8$ & $5 ø 14$ & $ø 8 / 8 m=2$ & $12 ø 18$ & $ø 10 / 10 m=4$ \\
\hline DCM $-0.3 g$ & $6 ø 18+6 ø 8$ & $5 ø 18$ & $ø 8 / 8 m=2$ & $12 ø 18$ & $ø 10 / 10 m=4$ \\
\hline $\mathrm{DCH}-0.3 g$ & $7 ø 14+6 ø 8$ & $7 ø 14$ & $ø 8 / 8 m=2$ & $12 ø 18$ & $ø 10 / 10 m=4$ \\
\hline
\end{tabular}

Table 3 Reinforcement for beams ends and columns for 8 - storey frames

\begin{tabular}{|c|c|c|c|c|c|c|}
\hline \multirow{3}{*}{\multicolumn{2}{|c|}{8 - storey frames }} & \multicolumn{3}{|c|}{ BEAMS } & \multicolumn{2}{|c|}{ COLUMNS $55 \times 55 \mathrm{~cm}$} \\
\hline & & \multicolumn{2}{|c|}{ Longitudinal reinf. } & \multirow{2}{*}{ Stirrup } & \multirow{2}{*}{ Longitudinal reinf. } & \multirow{2}{*}{ Stirrup } \\
\hline & & Top & Bottom & & & \\
\hline \multicolumn{2}{|c|}{ DCM - $0.2 g$} & $6 ø 16+7 ø 8$ & $5 ø 16$ & $\varnothing 8 / 9 m=2$ & $12 ø 18$ & $ø 10 / 10 m=4$ \\
\hline \multirow{2}{*}{$\mathrm{DCH}-0.2 \mathrm{~g}$} & 1. -4. & $5 ø 16+7 ø 8$ & $5 ø 16$ & $\varnothing 8 / 8 m=2$ & \multirow{2}{*}{$16 ø 16$} & \multirow{2}{*}{$ø 10 / 7.5 m=5$} \\
\hline & $5 .-8$. & $5 ø 14+7 ø 8$ & $5 ø 14$ & $ø 8 / 8 m=2$ & & \\
\hline \multicolumn{2}{|c|}{ DCM - $0.3 g$} & $6 ø 20+7 ø 8$ & $5 ø 20$ & $ø 10 / 10 m=2$ & $12 ø 20$ & $ø 10 / 10 m=4$ \\
\hline \multirow{2}{*}{$\mathrm{DCH}-0.3 g$} & 1. -5 . & $6 ø 16+7 ø 8$ & $6 ø 16$ & $ø 8 / 8 m=2$ & \multirow{2}{*}{$16 ø 16$} & \multirow{2}{*}{$ø 10 / 7.5 m=5$} \\
\hline & 6. -8. & $5 ø 14+7 ø 8$ & $5 ø 14$ & $ø 8 / 8 m=2$ & & \\
\hline
\end{tabular}

Table 4 Reinforcement for beams ends and columns for 10 - storey frames

\begin{tabular}{|c|c|c|c|c|c|c|}
\hline \multirow{3}{*}{\multicolumn{2}{|c|}{10 - storey frames }} & \multicolumn{3}{|c|}{ BEAMS } & \multicolumn{2}{|c|}{ COLUMNS $60 \times 60 \mathrm{~cm}$} \\
\hline & & \multicolumn{2}{|c|}{ Longitudinal reinf. } & \multirow{2}{*}{ Stirrup } & \multirow{2}{*}{ Longitudinal reinf. } & \multirow{2}{*}{ Stirrup } \\
\hline & & Top & Bottom & & & \\
\hline \multicolumn{2}{|c|}{ DCM - $0.2 g$} & $6 ø 16+7 ø 8$ & $5 ø 16$ & $\varnothing 8 / 9 m=2$ & $12 \varnothing 20$ & $ø 10 / 10 m=4$ \\
\hline \multirow{2}{*}{$\mathrm{DCH}-0.2 \mathrm{~g}$} & 1. -5 . & $5 ø 16+7 ø 8$ & $5 ø 16$ & $ø 10 / 9 m=2$ & \multirow{2}{*}{$16 ø 18$} & \multirow{2}{*}{$ø 10 / 10 m=5$} \\
\hline & 6. -10 & $5 ø 14+7 ø 8$ & $5 ø 14$ & $ø 10 / 10 m=2$ & & \\
\hline \multicolumn{2}{|c|}{ DCM-0.3 $g$} & $6 ø 20+7 ø 8$ & $5 ø 20$ & $ø 10 / 10 m=2$ & $12 ø 20$ & $ø 10 / 10 m=4$ \\
\hline \multirow{2}{*}{$\mathrm{DCH}-0.3 g$} & $1 .-5$. & $5 ø 18+7 ø 8$ & $5 ø 18$ & $\varnothing 10 / 10 m=2$ & \multirow{2}{*}{$16 ø 18$} & \multirow{2}{*}{$ø 10 / 10 m=$} \\
\hline & 6. -10 . & $5 ø 16+7 ø 8$ & $5 ø 16$ & $ø 10 / 9 m=2$ & & \\
\hline
\end{tabular}

\subsection{Nonlinear Static and Dynamic Analysis}

The considered frames are evaluated for the SD limit state, i.e. design seismic action. Nonlinear analysis method is the reference method for the evaluation of seismic performance.

Nonlinear static analysis is carried out under constant gravity loads and monotonically increasing lateral loads 
applied at the location of the masses in the model. According to EN 1998, at least two vertical distributions of lateral loads should be applied: a modal pattern, the inverse triangular distribution - linear $(L)$, and a uniform distribution $(U)$. When applying lateral force, the response of a structure is monitored and the target displacement is determined by N2 method. The target displacement is global seismic demand. The demands at local level, chord rotations at both ends of each structural member, are those that correspond to the target displacement.

A nonlinear dynamic analysis provides the response of a construction due to a real recorded earthquake. The EN 1998 provisions require at least three different records. The values of the earthquake record should be scaled to the value of $a_{g}: S$ for the considered seismic zone. The suite of accelerograms to be used should satisfy the requirement that the mean of the zero-period spectral response acceleration values should not be smaller than the value of the $a_{g} S$ for the observed location. Also, in the range of periods between $0,2 T_{1}$ and $2 T_{1}$, no value of the mean elastic spectrum with 5\% damping, calculated from all time histories, should be less than $90 \%$ of the corresponding value of the $5 \%$ damping elastic response spectrum. Acceleration records can be artificial, recorded or simulated. It is generally recognized that recorded accelerograms, if they are well selected, are less demanding for the construction than the generated accelerograms, because the recorded accelerograms do not match so well the elastic response spectrum and the frequency composition of such records, and are limited in relation to the elastic response spectrum [21]. In case of generated accelerograms each single accelerogram has a response spectrum close to the elastic response spectrum and an excitation with a smooth response spectrum without peaks or troughs introduces a conservative bias in the response [16].

Two sets (for $a_{g}=0,2 g$ and $a_{g}=0,3 g$ ) with three real earthquake records were selected for nonlinear dynamic analysis (Fig. 3 and Fig. 4), according to the selection procedure given in Eurocode 8). The records were selected from the PEER database [22] and scaled according to EN 1998-1.
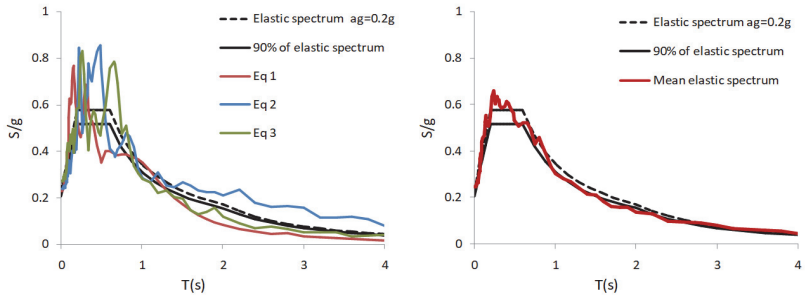

Figure 3 Response spectra and mean values of selected records, elastic spectrum and $90 \%$ of elastic spectrum for seismic action $a_{g}=0,2 \mathrm{~g}$
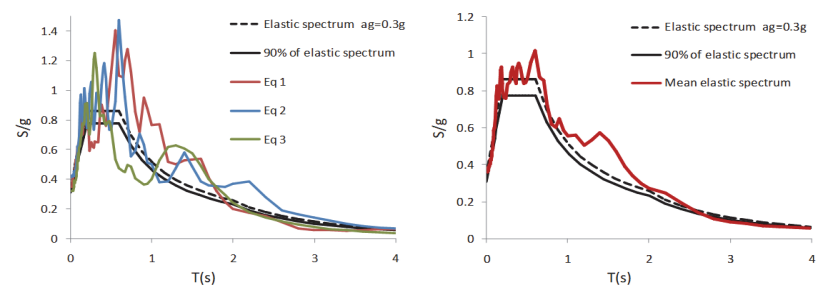

Figure 4 Response spectra and mean values of selected records, elastic spectrum and $90 \%$ of elastic spectrum for seismic action $a_{g}=0,3 \mathrm{~g}$

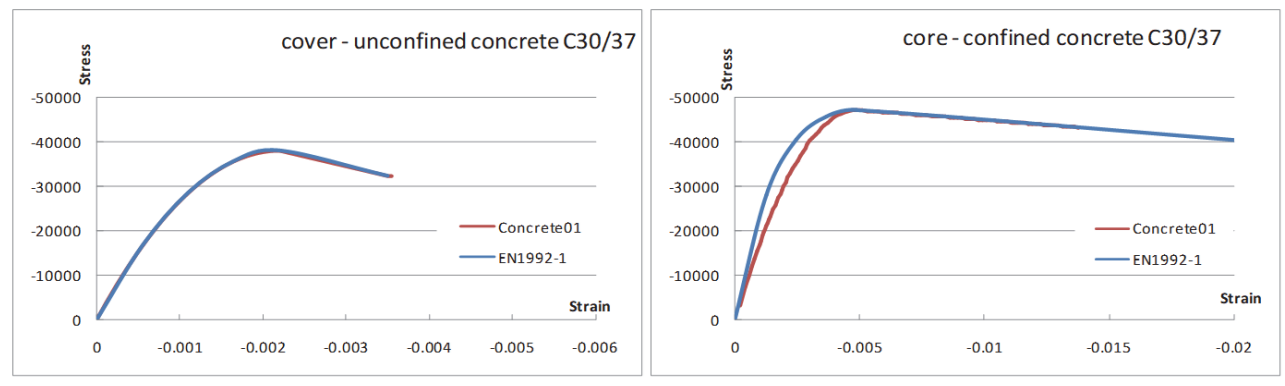

Figure 5 Stress-strain diagrams for concrete according to "Concrete01" and EN 1992-1-1 model

Nonlinear analyses were conducted using program OpenSees [23]. The beams and columns were modelled using "Force-Based Beam-Column Element" that considers the spread of plasticity along the length of the element. The integration along the element was based on Gauss-Lobatto quadrature. In each integration point, cross section was presented with fibre model, which was defined by three kinds of fibre: unconfined concrete (cover), confined concrete (core) and reinforcement. The concrete was modelled by the uniaxial material "Concrete 01 ", the steel was modelled by the uniaxial material "Steel02". "Concrete $01 "$ describes stress-strain behaviour of concrete, according to Kent-Scott-Park concrete material, in compression with parabolic pre-peak and linear post-peak while tensile strength is zero. At cyclic loading, the stressstrain behaviour is according to the Karsan -Jirsa model, with linear branches including degraded stiffness [23]. For nonlinear structural analysis, EN 1992-1-1 [24] describes stress-strain relation of concrete with parabolic. Fig. 5 compares the stress-strain diagrams for concrete according to model"Concrete01" and EN 1992-1-1, for the unconfined and confined concrete of a column of one of the analysed frames. The strength of confined concrete, the strain that corresponds to that strength and the ultimate strain of the extreme fibre of the compression zone are evaluated according to EN 1998-3 Annex A. "Steel02" describes steel material with isotropic strain hardening according to Giuffre-Menegotto-Pinto steel model. This model includes bilinear stress-strain envelope and allows control transition from linear to nonlinear branch [23]. "Steel02" accounts for the Baushinger effect but does not include degradation due to bar buckling and fatigue [25].

One of OpenSees commands for creating the output is "Recorder Command". "Recorder Command" is used to monitor user defined parameters in the model during the analysis and to generate output. "Element Recorder" 
monitors what is happening in the element, in the section or fibre at every converged step and depends on the element type. For "Force-Based Beam-Column Element", among others, valid responses are "tangentDrift" and "inflectionPoint". The response determined as "tangentDrift" means the drift between element ends and inflection point of this element. Based on those responses chord rotation demand can be evaluated as element drift ratio. In this way estimated response is valid at columns. Tangent drift and inflection point are not valid for beams, because inflection point is determined as the ratio moment and shear at the element end and does not take into account the gravity loads of the beams. For this reason, chord rotation demand at beams was evaluated as mentioned above. For "Force-Based Beam-Column Element" response "basicDeformation" gives element end rotationfrom the chord of element to the tangent of element end, both in deformed state of element.

\subsection{Results and Discussion}

In the numerical analysis results and discussion, the considered frames are named according to the number of storeys, the ductility class and the intensity of seismic action.

Based on the estimated maximum base shear (actual strength) and design strength, reserve strength of the frames was determined and shown depending on the load pattern $(L$ or $U)$, for the different number of storeys $(4,6$, 8 and 10), the intensity of the design seismic action $(0,2 \mathrm{~g}$ or $0,3 \mathrm{~g}$ ) and two ductility classes (DCM and DCH) (Fig. $6)$. Due to the lateral load $U$, higher values of actual strength were obtained and thus the higher values of reserve strength.

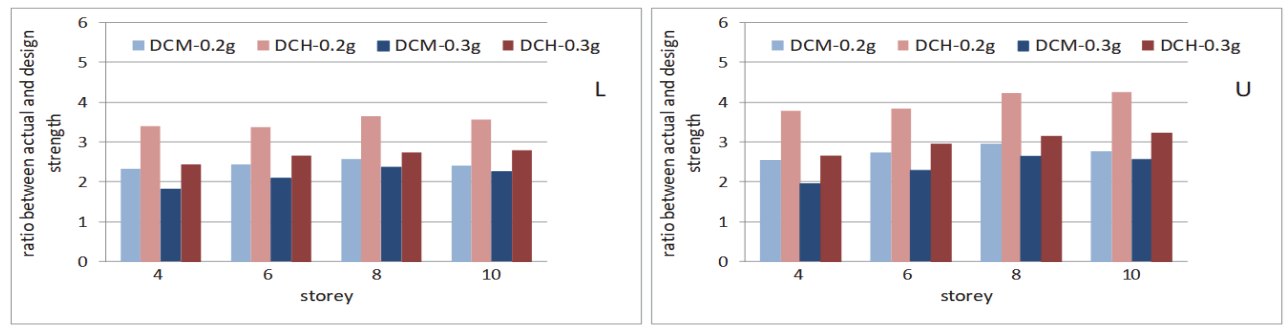

Figure 6 Ratio between actual and design strength for analysed frames

There was a pronounced influence of the intensity of the design seismic action, as well as ductility classes on these values. The frames designed for $0,2 \mathrm{~g}$ have a greater reserve strength in comparison to the frames designed for $0,3 \mathrm{~g}$, which is, for DCM frames, up to $30 \%$ higher, and for DCH frames up to $40 \%$. The higher reserve strength occurs with $\mathrm{DCH}$ frame in comparison to DCM frame, in range from $16 \%$ to $48 \%$ for the load pattern $L$, and between $19 \%$ and $52 \%$ for the load pattern $U$. The frame storey number itself has less effect, but it could be noticeable that the frames with greater number of storeys had greater reserve strength.

The chord rotation capacity of each element of the analysed frames for the NC limit state is determined by Eq. (1). As noted above, on these values influence, inter alia, the axial forces $N$ and shear span $L_{v}$, two values that are variable due to a seismic action.

When calculating chord rotation capacity of beams, the assumed value of axial force was zero, while, in case of calculating chord rotation capacity of columns, the value of axial force due to seismic load combination was adopted. At both the beams and the columns, an approximate value of the shear span corresponding to half length of the element was adopted. The influence of the change of normal force $N$ and the shear span $L_{v}$ on the determination of the value of the chord rotation capacity is shown in the examples of the external ground column of the $4 \mathrm{~s}-\mathrm{DCM}-0.3 \mathrm{~g}$ and $4 \mathrm{~s}-\mathrm{DCH}-0.3 \mathrm{~g}$ frames (Fig. 7). The diagrams of estimated chord rotations and bending moments at the nonlinear static analysis, as well as the capacities of the chord rotation of the observed element are shown on the left. The dash line shows the chord rotation capacity with constant values for $N$ and $L_{v}$ (as mentioned above), the blue line shows the value of the chord rotation capacity determined on the basis of the change $L_{v}$, the green line when considering the change of $N$ and with the red line the chord rotation capacity in dependencies of both variable $N$ and $L_{v}$, during the pushover analysis. On the right side, only the change of the chord rotation capacity in the postelastic zone is shown. The changeable values of chord rotation capacity decrease in nonelastic region (blue, green and red lines). The constant value of the chord rotation capacity is smaller (on the safe side) than the calculated value that took into account the change of $N$ and $L_{v}$ (the red line), to reach the maximum bending moment. After reaching the maximum moment there is a zone where the constant capacity is higher (more pronounced at the $4 \mathrm{~s}$ - DCM - $0.3 g$ frame). When assessing the element for NC limit state this should be considered. The chord rotation demands $\left(\theta_{\text {demand }}\right)$ of all elements of the considered frames were evaluated the nonlinear static analysis, for two lateral force distribution ( $L$ and $U$ ), and the nonlinear dynamic analysis, for the corresponding set of three earthquake records (Eq. (1), Eq. (2) and Eq. (3)).The following diagrams (Fig. 8) show the ratio between the chord rotation demand and the appropriate capacity for SD limit state $\left(\theta_{\mathrm{SD}}\right)$ of columns and beams at critical section. The critical sections of columns are at the fixed ends of exterior columns. In case of frames with a smaller number of storeys maximum values of chord rotation demand have been reached in the beams of first storey, and for frames with a number of storeys, at the beams of higher levels of storeys, depending on the seismic excitation. 


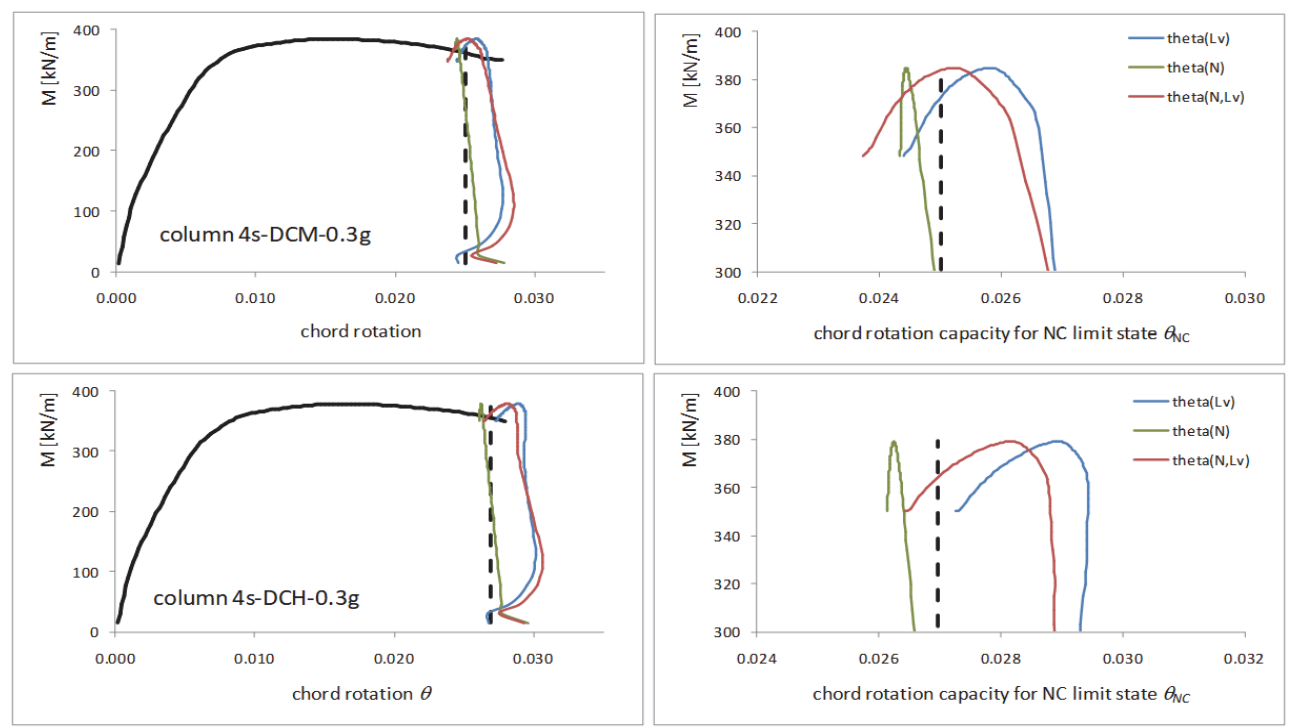

Figure 7 The influence of the change of axial force and shear span at monotone load on the value of the chord rotation capacity
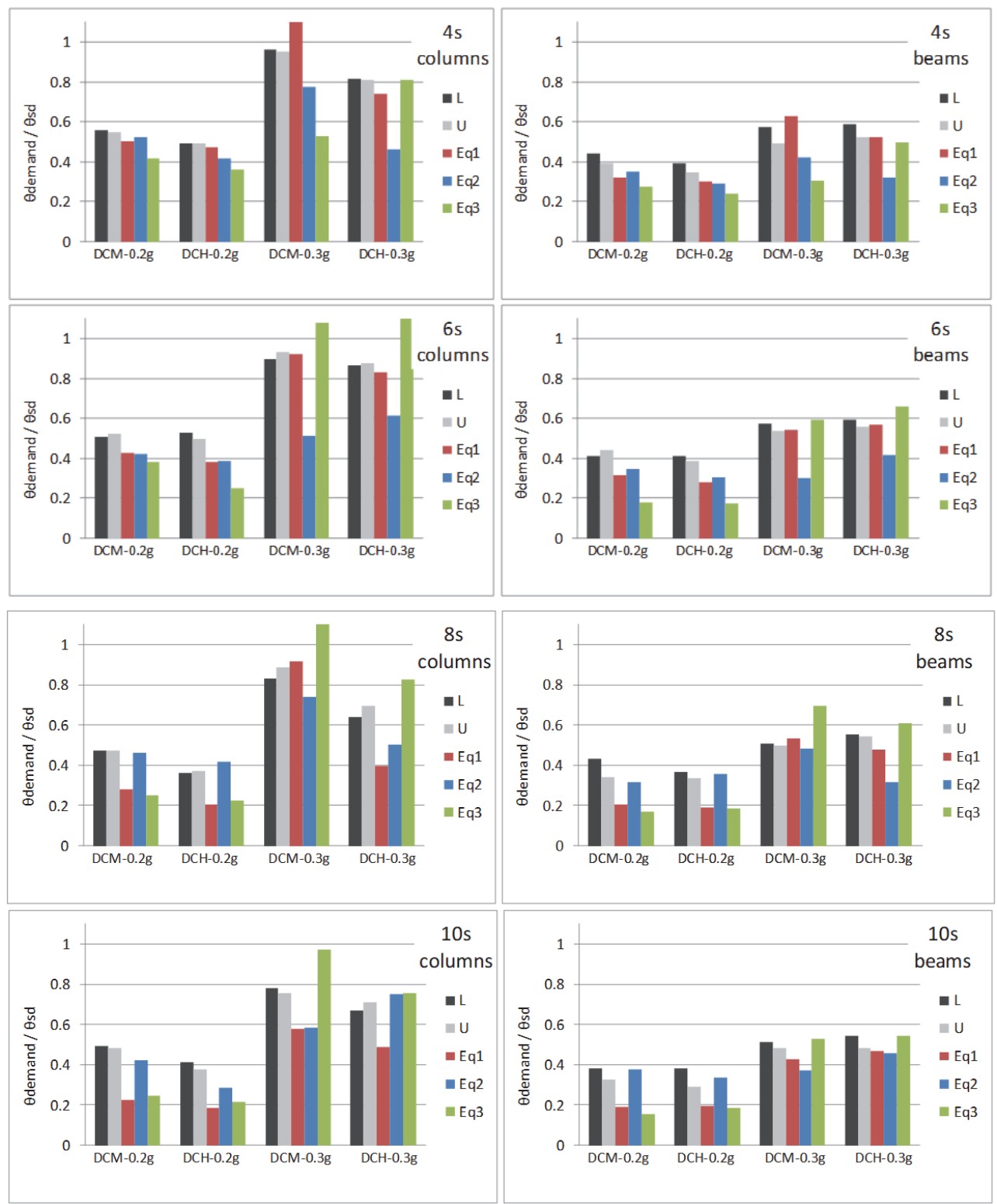

Figure 8 Chord rotation demand and capacity ratio for SD limit state

Based on the results of the pushover analyses at the columns of all the considered frames, the estimated chord rotation demands are lower than the corresponding capacities. With the increase in the number of storey 
frames, the values of the ratio $\theta_{\text {demand }} / \theta_{\mathrm{SD}}$ decrease. For frames designed for seismic action of $0,2 \mathrm{~g}, \theta_{\text {demand }} / \theta_{\mathrm{SD}}$ ratio is smaller than $0,3 \mathrm{~g}$ of frames. Also, the frames designed for high ductility class have lower values of these ratios compared to frames designed for middle ductility class. On the basis of the time history analysis, chord rotation demands of columns are considerably smaller than the capacity for the frames designed for seismic action 0,2 $g$. The columns of the DCM frames with 4,6 and 8 storeys designed for $0,3 \mathrm{~g}$ seismic action have, as a result of one seismic excitation, the value of chord rotation demand greater than the capacity for SD limit state. This is also the case with the DCH frames with 6 storeys designed for the same seismic action.

The estimated chord rotation demands for all the frames considered are smaller than the corresponding capacities based on the pushover and time history analysis. The frames designed for $0,2 \mathrm{~g}$ seismic actions have a lower value of $\theta_{\mathrm{demand}} / \theta_{\mathrm{SD}}$ ratio compared to the frames designed for $0,3 g$ seismic action.

\section{CONCLUSION}

Design of structures in seismically active areas according to EN 1998-1 includes a choice between two ductility classes, medium or high, without conditioning with other parameters or favouring of any of them. The difference between choices reflects, beside the behaviour factor values, additional requirements for local ductility. Selection of ductility class defines structural capacity and ductility, and also assumes the structural performance due to earthquake. The research in this paper was focused on the study of influence of the design ductility classes, as well as of the design seismic actions and the number of frames storeys, on seismic response of RC frames designed according to European codes.

RC frames with different number of storeys (4, 6, 8 and $10)$, two ductility classes (DCM and DCH) and two design seismic actions $(0,2 \mathrm{~g}$ and $0,3 \mathrm{~g})$ were designed according to European codes and analysed for SD limit state according to EN 1998-3. The seismic actions for this limit state are equal to the designed seismic actions. The assessment was conducted using nonlinear static analysis for two lateral load distributions and nonlinear dynamic analysis for three recorded earthquakes.

The available strength of structure represents an important factor, which could directly affect the structural performance during stronger seismic actions than the designed ones. The greater overstrength factor, which was obtained for frames designed for $0,2 \mathrm{~g}$ as well as for $\mathrm{DCH}$ frames, results from a greater influence of gravity loads. For DCH frames, the rigorous provisions aimed at improvement of ductility during design, also contribute to increase of the strength reserve. For the reasons mentioned, the more favourable seismic performance of these frames was expected.

The seismic assessment for ductile elements was determined by verifying that chord rotation demands of elements do not exceed the corresponding capacities according to EN 1998-3 provisions. Based on the assessment, all members of newly designed RC frames met the requirements of SD limit state, when a pushover analysis was applied. In application of nonlinear dynamic analysis, for one recorded earthquake the critical section of columns of the DCM - 0,3 $g$ frames with 4, 6 and 8 storeys did not meet the SD requirements. Higher values of ratio $\theta_{\mathrm{demand}} / \theta_{\mathrm{SD}}$ were estimated on critical sections of columns comparing to the beams. As expected, frames designed for lower seismic action had lower values of this ratio. Based on the performed numerical research, it was noticed that the estimated seismic demands obtained by the application of nonlinear static analysis are on safe side only for the frames designed for a lower level of seismic action compared to the results obtained by the application of the nonlinear dynamic analysis.

\section{Acknowledgements}

The project presented in this article is supported by the scientific research project TR 36043 "Development and application of a comprehensive approach to the design of new and safety assessment of existing structures for seismic risk reduction in Serbia", which is funded by the Ministry of Science of Serbia.

\section{REFERENCES}

[1] Kalkan, E. (2006). Prediction of seismic demands in building structures. (Doctoral dissertation)

[2] Kalman, Š. T. \& Hadzima-Nyarko, M. (2018). Seismic Risk of Croatian Cities Based on Building's Vulnerability. Technical Gazette, 25(4), 1088-1094. https://doi.org/10.17559/TV-20170708190145

[3] EN 1998-1:2004 Eurocode 8: Design of structures for earthquake resistance. Part 1, General rules, seismic actions and rules for buildings. (2004). Brussels: CEN.

[4] Isik, E. \& Kutanis, M. (2015). Performance based assessment for existing residential buildings in Lake Van basin and seismicity of the region. Earthquake and Structures, 9(4), 893-910. https://doi.org/10.12989/eas.2015.9.4.893

[5] EN 1998-3:2005 Eurocode 8: Design of structures for earthquake resistance. Part 3, Assessment and retrofitting of buildings. (2005). Brussels. CEN.

[6] Manfredi, V. \& Masi, A. (2017). Consistency of analysis methods considered in EC8-3 for the seismic assessment of RC existing buildings. Bulletin of Earthquake Engineering, 15(7), 3027-3051. https://doi.org/10.1007/s10518-016-0070-x

[7] Romão, X., Delgado, R., Guedes, J., \& Costa, A. (2010). A comparative application of different EC8-3 procedures for the seismic safety assessment of existing structures. Bulletin of Earthquake Engineering, 8(1), 91-118. https://doi.org/10.1007/s10518-009-9123-8

[8] Magliulo, G., Maddaloni, G., \& Cosenza, E. (2007). Comparison between non-linear dynamic analysis performed according to EC8 and elastic and non-linear static analyses. Engineering Structures, 29(11), 2893-2900. https://doi.org/10.1016/j.engstruct.2007.01.027

[9] Ademovic, N., Hrasnica, M., \& Oliveira, D. V. (2013). Pushover analysis and failure pattern of a typical masonry residental building in Bosnia and Herzegovina. Engineering Structures, 50, 13-29. https://doi.org/10.1016/j.engstruct.2012.11.031

[10] Krawinkler, H. \& Seneviratna, G. D. P. K. (1998). Pros and Cons of a Pushover Analysis of Seismic Performance Evaluation. Engineering Structures, 20(4-6), 452-464. https://doi.org/10.1016/S0141-0296(97)00092-8

[11] Charney, F., Tola T. A, \& Atlayan, O. (2012). Structural Analysis.Fema P-751: NEHRP Recommended Provisions: Design Examples. Chapter 4 
[12] Chopra, A. K. \& Goel, R. K. (2002). A modal pushover analysis procedure for estimating seismic demands for buildings. Earthquake Engineering \& Structural Dynamics, 31(3), 561-582. https://doi.org/10.1002/eqe.144

[13] Kreslin, M. \& Fajfar. P. (2012). The Extended N2 Method Considering Higher Mode Effects in both Plan and Elevation. Bulletin of Earthquake Engineering, 10(2), 695715. https://doi.org/10.1007/s10518-011-9319-6

[14] Hsiao, F. P., Oktavianus, Y., \& Ou, Y. C. (2015). A pushover seismic analysis method for asymmetric and tall buildings. Journal of the Chinese Institute of Engineers, 38(8), 9911001. https://doi.org/10.1080/02533839.2015.1056553

[15] Elnashai, A. S. \& Di Sarno, L. (2015). Fundamentals of earthquake engineering: From source to fragility. Chichester: John Wiley \& Sons.

[16] Fardis, M. N. (2009).Seismic Design, Assessment and Retrofitting of Concrete Buildings: Based on EN-Eurocode 8. Geotechical, Geological and Earthquake Engineering, 8. London. Springer. https://doi.org/10.1007/978-1-4020-9842-0

[17] Panagiotakos, T. B. \& Fardis, M. N. (2001). Deformations of Reinforced Concrete Members at Yielding and Ultimate. ACI Structural Journal, 98(2), 135-148. https://doi.org/10.14359/10181

[18] Biskins, D. E. \& Fardis, M. N. (2007). Effect of lap splices on flexural resistance and cyclic deformation capacity of RC members. Beton- und Stahlbetonbau, 102(S1), 51-59. https://doi.org/10.1002/best.200710105

[19] Peruš, I., Poljanšek, K., \& Fajfar, P. (2006). Flexural deformation capacity of rectangular RC columns determined by the CAE method. Earthquake Engineering \& Structural Dynamics, 35(12), 1453-1470. https://doi.org/10.1002/eqe.584

[20] Mpampatsikos, V., Nascimbene, R., \& Petrini, L. (2008). A Critical Review of the R.C. Frame Existing Building Assessment Procedure According to Eurocode 8 and Italian Seismic Code. Journal of Earthquake Engineering, 12(Sup1), 52-82. https://doi.org/10.1080/13632460801925020

[21] Spacone, E., Camata, G., \& Fagella, M. (2007). Nonlinear models and nonlinear procedures for seismic analysis of reinforced concrete frame structures. Chapter in book: Computational Structural Dynamics and Earthquake Engineering, 323-345. https://doi.org/10.1201/9780203881637.ch21

[22] PEER database, download 20.02.2014., http://peer.berkeley.edu/smcat/search.html

[23] Mazzoni, S., McKenna, F., Scott, M., \& Fenves, G. L. (2007). OpenSees Command Language Manual. PEER Center. University of California. Berkeley.

[24] EN 1992-1-1:2004 Eurocode 2: Design of concrete structures. Part 1-1, General rules and rules for buildings. (2004). Brussels: CEN.

[25] Kashani, M. M., Crewe, A. J., Alexander, N. A. \& Lowes, L. N. (2015). Reliably predicting the nonlinear cyclic response of RC bridge piers up to complete collapse. Proceedings of SECED Conference-Earthquake Risk and Engineering towards a resilient world. Cambridge. UK. 6-9 July.

[26] Isik, E. \& Ozdemir, M. (2017). Performance Based Assessment of Steel Frame Structures by Different Material Models. International Journal of Steel Structures, 17(3), 1021-1031. https://doi.org/10.1007/s13296-017-9013-x

\section{Contact information:}

Aleksanra RADUJKOVIĆ, PhD, Civ.Eng., Assistant Professor Universit of Novi Sad, Faculty of Technical Sciences, Trg Dositja Obradovića 6, 21000 Novi Sad, Republic of Serbia E-mail: leksa@uns.ac.rs

Đorđe LAEINOVIĆ, PhD, Civ.Eng., Full Professor (Corresponding author)

University of Novi Sad, Faculty of Technical Sciences, Trg Dositeja Obradovića 6, 21000 Novi Sad, Republic of Serbia E-mail: ladjin@uns.ac.rs

Andrija RAŠETA, PhD, Civ.Eng., Assistant Professor University of Novi Sad, Faculty of Technical Sciences, Trg Dositeja Obradovića 6, 21000 Novi Sad, Republic of Serbia E-mail: araseta@uns.ac.rs 